\title{
ARQUIVOS UNIVERSITÁRIOS: O CASO DA UNIVERSIDADE DE HAMBURGO
}

\author{
UNIVERSITY ARCHIVES: THE CASE OF THE \\ UNIVERSITY OF HAMBURG
}

Maria Juliana Nunes da Silvaa

Ivana Denise Parrelab

\begin{abstract}
RESUMO
Introdução: O trabalho discorre sobre as universidades e seus arquivos e relata uma experiência no arquivo da universidade de Hamburgo. Objetivo: Pretendeu-se expandir o conhecimento sobre uma realidade arquivística pouco conhecida. Metodologia: Foi realizada pesquisa bibliográfica e visita técnica ao arquivo da universidade para conhecer o trabalho. Resultados: A Universidade de Hamburgo tem uma boa estrutura física e de gestão e conta com instrumentos arquivísticos para a organização dos arquivos. Conclusões: Foi perceptível a preocupação da Universidade de Hamburgo com a preservação de sua história por meio dos seus documentos. O Brasil, em termos de teoria e gestão de boas práticas, não está atrás em nada de um país como a Alemanha, o que algumas instituições precisam é de mais recursos humanos especializados e infraestrutura adequada de arquivo.
\end{abstract}

Descritores: Universidade. Arquivos. Universidade de Hamburgo. Arquivos universitários.

\section{INTRODUÇÃO}

O surgimento das universidades versa o final do século $\mathrm{XI}$, em Bolonha na Itália e vai expandindo nos séculos seguintes na Inglaterra, França, Espanha, Portugal e assim por diante em vários outros países.

Segundo Simões (2013) houve uma expansão de universidades por todo o território europeu nos séculos XIII, XIV e XV e na Idade Média, época do surgimento das universidades, o conceito de "universidade" era visto pelo

a Doutoranda no Programa de Pós-Graduação em Ciência da Informação e arquivista da Universidade Federal de Minas Gerais/UFMG. E-mail: mariajulianasilva.js@gmail.com

b Professora associada da Escola de Ciência da Informação da Universidade Federal de Minas Gerais/UFMG. E-mail: ivanaparrela@ufmg.br 
enorme prestígio dado à educação da sociedade da época.

Mas foi na instituição da chamada "universidade moderna" que preceitos conhecidos hoje surgiram no famoso texto de Humboldt" "Sobre a organização interna e externa das instituições científicas superiores em Berlim", e tem a reflexão mais significativa e concisa sobre a universidade (PEREIRA, 2009).

Ainda segundo Pereira (2009, p. 31):

Os princípios essenciais postulados por Humboldt - de forma geral, até hoje defendidos como formulações que dão à universidade seu caráter próprio - são essencialmente: a formação através da pesquisa; a unidade entre o ensino e pesquisa; a interdisciplinaridade; a autonomia e a liberdade da administração da instituição e da ciência que ela produz; a relação integrada, porém autônoma, entre Estado e Universidade; a complementaridade do ensino fundamental e médio com o universitário.

[...] O que caracterizou a universidade, chamada agora de moderna, é essencialmente a associação programática entre ensino e pesquisa. O terceiro elemento do tripé, a extensão, apareceu mais tarde, com o modelo da universidade norteamericana. [...]

O modelo alemão de Humboldt não é o único entre as universidades do mundo ocidental que se constituíram como instituição da modernidade, mas é uma importante referência e como nesse trabalho se discorre sobre uma universidade alemã, os pressupostos de Humboldt na Alemanha são respeitados e sua citação é um embasamento preponderante nessa introdução sobre o tema.

Chaui (2003) ressalta que hoje a universidade é uma instituição social e como tal exprime de maneira determinada a estrutura e o modo de funcionamento da sociedade como um todo e sendo uma instituição social as mudanças acompanham as transformações sociais, econômicas e políticas, mas o cerne ensino e pesquisa continua sendo o vetor existencial da universidade em qualquer lugar do mundo.

E como em qualquer instituição a universidade tem suas funções $e$ atividades refletidas em forma de documentos, documentos de arquivo

\footnotetext{
1 Wilhelm von Humboldt foi o fundador da Universidade de Berlim, em 1808 (hoje, Humboldt Universität) e particularmente reconhecido como tendo sido o pai do sistema educacional alemão.
} 
produzidos e acumulados em decorrência de suas atividades meio e finalísticas ${ }^{2}$, executadas por seus setores estruturantes.

Trabalhando em uma universidade no Brasil e conhecendo seus arquivos, esse artigo é resultado de um intercâmbio na Alemanha cujo objetivo foi estar em contato e conhecer um pouco dos arquivos daquele país, mais especificamente os universitários.

Escrever sobre tal experiência se dá em função da oportunidade e desafio de contato com uma realidade tão diferente em termos culturais e históricos. Objetiva-se que este artigo possa contribuir para ampliar a visão sobre uma área específica de arquivos na Alemanha e que pouco se discorre no campo da arquivística.

\section{A IMPORTÂNCIA DOS ARQUIVOS UNIVERSITÁRIOS}

Em qualquer instituição os arquivos, que são produzidos organicamente, refletem inicialmente as ações realizadas para cumprir sua missão e consequentemente se tornam a história/memória desta.

Menezes (2012) ressalta que este conjunto informacional, adquirido por meio das fontes documentais arquivísticas, compõe grande parte do patrimônio informacional da universidade e a principal base do saber produzido por sua comunidade acadêmica.

Carpes e Flores (2013, p. 15) levantam a questão do reconhecimento dos arquivos, mais especificamente dos arquivos permanentes, como patrimônio documental e importantes na constituição da memória.

Nota-se que os documentos/arquivos são claramente citados como integrantes do Patrimônio Cultural, tanto na definição da UNESCO, como na definição da nossa Constituição. Cabe destacar que os arquivos são considerados parte do Patrimônio Cultural porque são compostos pelo "Patrimônio Documental". Neste sentido, o Patrimônio Documental é, segundo a UNESCO, o conjunto de documentos conservados ou reunidos no exercício de sua função por qualquer organismo ou entidade de caráter público, privado, religioso, particular, que fomentem parte da

\footnotetext{
${ }^{2}$ Atividade-meio - Atividade que dá apoio à consecução das atividades-fim de uma instituição. Também chamada atividade mantenedora. Atividade-fim - Atividade desenvolvida em decorrência da finalidade de uma instituição. Também chamada atividade finalística. (Dicionário de Terminologia Arquivística, 2005, p. 39)
} 
memória da nação. [...]

Neste sentido, os documentos considerados patrimônio documental são, portanto, os que possuem valor secundário ou permanente.

O patrimônio documental e a memória preservada da universidade traz à mostra não só o resgate das ações registradas para cumprir suas funções, mas torna acessível a prestação de contas do que foi investido em termos de recursos financeiros com a instituição por meio dos seus produtos, traz à tona a evolução dos resultados em termos de conhecimento, formação, pesquisa e acesso à informação para a sociedade.

Jardim colocou muito bem o uso dos arquivos permanentes: "De um lado, em função do uso desses documentos para a pesquisa científica e, de outro, como fator de testemunho das ações do Estado e garantia de direitos dos cidadãos" (JARDIM, 1995, p. 3 apud CARPES E FLORES, 2013, p. 14).

A dissociação entre arquivo e memória é quase impossível, pois são nos documentos de arquivo que a memória institucional é reproduzida, torna-se fonte de pesquisa e de acesso a informação, além de importante insumo estratégico para a tomada de decisão.

Pereira (2011, p. 24 apud MERLO; KONRAD, 2015, p. 35) assim reflete: "Visto que os documentos são uma forma de expressão da memória, então os arquivos são os detentores da memória individual e coletiva, servindo de suporte para a constituição da história das instituições e da identidade de um determinado povo."

Conforme Belloto (1989, p. 20-21) os arquivos constituem fontes de informação:

\begin{abstract}
Esses documentos são conservados enquanto seu teor está em vigor/vigência, por razões administrativas e/ou jurídico-legais, podendo ser eliminados se o seu valor se restringir àquele uso primário (o relacionado ao motivo da sua produção) ou, sendo documento de valor permanente, vir a constituir elemento documental dentro dos arquivos permanentes, comumente conhecidos como históricos.
\end{abstract}

Para ela um sistema de arquivo em cada universidade deve e pode criar condições de otimização das funções-fins de ensino, pesquisa e extensão, ademais das próprias atividades-meio, com a devida implantação de programas de gestão de documentos. 
Os autores Carpes e Flores (2013) ainda discorrem sobre a riqueza do arquivo universitário:

Ressalta-se a riqueza do acervo dessas instituições que resguardam a prova de atividades de ensino, pesquisa e extensão. Por meio das reflexões realizadas é possível inferir que 0 arquivo universitário deve ser um dos principais custodiadores da memória institucional, pois nele está preservado e disponibilizado o patrimônio documental da universidade. (CARPES; FLORES, 2013, p. 20-21)

Em qualquer universidade do mundo é preciso que os arquivos sejam preservados, que se tenha gestão de documentos e regras claras de organização, destinação e guarda do patrimônio documental fonte de pesquisa e memória para estudantes, professores, pesquisadores e para a sociedade de um modo geral.

\section{O ARQUIVO DA UNIVERSIDADE DE HAMBURGO}

A Alemanha conta com centenas de universidades e faculdades e a mais antiga, fundada no ano de 1386, é a Ruprecht-Karls-Universität Heidelberg.

Nesse artigo a experiência relatada é sobre a Universidade de Hamburgo, que se mostrou interessante discorrer pois no ano de 2019 ela completou 100 anos, então não é uma universidade tão antiga, tem uma boa estrutura física e de gestão de arquivo e possui instrumentos arquivísticos.

Fazer intercâmbio na Alemanha agregou muito em conhecimento profissional e acadêmico, pois pouco se publica na literatura internacional sobre os arquivos desse país e estar in loco faz toda a diferença no entendimento de uma realidade pouco conhecida. No caso em questão a metodologia utilizada foi a realização de visita técnica ao arquivo da universidade, além de pesquisa bibliográfica.

Os arquivos na Alemanha abordam os mesmos problemas de diferentes maneiras. Os arquivos, em alguns casos, sofrem com poucos recursos financeiros e/ou humanos, como exemplo existem arquivos que contam com uma pessoa apenas. O termo teoria das três idades, tão consolidado no Brasil, é mais conhecido como ciclo de vida e existe uma clara delimitação entre os arquivos ativos e históricos. Em alguns arquivos universitários a área de gestão 
de documentos (records management em inglês ou schriftgutverwaltung em alemão) é totalmente separada do arquivo histórico e o tratamento dos documentos só é feito quando se chega ao arquivo, em outros casos o arquivo histórico interage com a área de gestão de documentos em colaboração. Este é o caso do Arquivo da Universidade de Hamburgo, Universitätsarchiv Hamburg (UAHH) em alemão.

$\mathrm{Na}$ figura abaixo é possível visualizar tal estrutura, adaptada do organograma do Arquivo:

Figura 1 - Organigramm Universitätsarchiv Hamburg

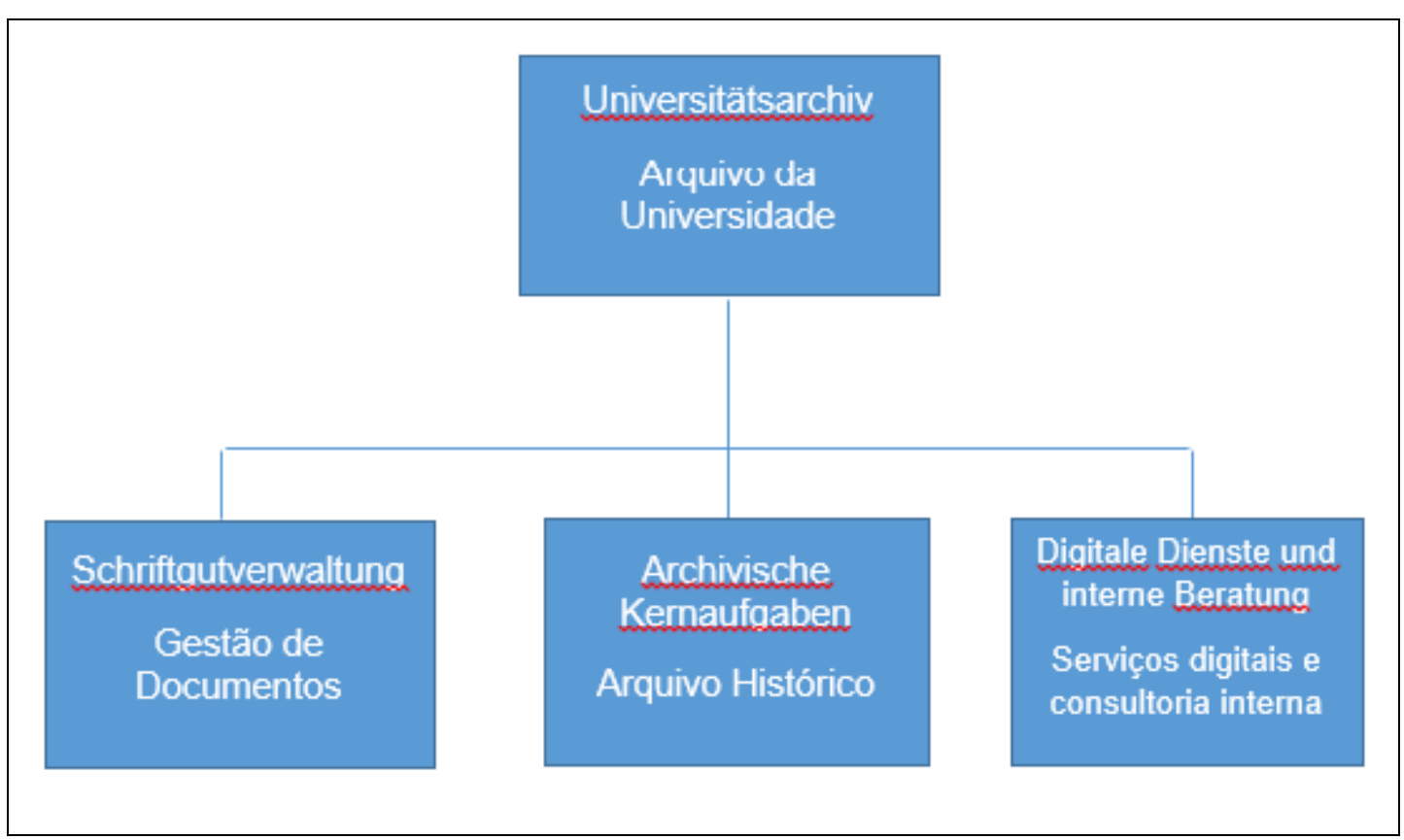

Fonte: Adaptado do organograma Universitätsarchiv Hamburg (2019, tradução nossa)

Neste organograma o setor de gestão de documentos, o arquivo histórico e o setor de serviços digitais fazem parte da estrutura do que conhecemos comumente como arquivo central. Esta não é uma realidade em todas as universidades, como mencionado existem casos em que o setor de gestão de documentos está totalmente separado estruturalmente do arquivo. No caso da universidade de Hamburgo não há arquivistas neste setor, só no arquivo histórico e eles trabalham juntos na coordenação dos processos de entrega dos arquivos intermediários para o histórico. A monitorização da gestão de registos na Universidade de Hamburgo é da responsabilidade do Arquivo Central (UAHH). 
O Arquivo da Universidade de Hamburgo é responsável pelo gerenciamento eficiente, bem organizado e legalmente compatível dos registros e pelo armazenamento e fornecimento permanente dos registros historicamente e legalmente significativos (arquivamento).

Conforme consta na sua página eletrônica, as atribuições do Universitätsarchiv Hamburg (2019, tradução nossa) são:

- Assessoria em questões relativas à gestão de registros para todas as instituições da Universidade de Hamburgo.

- Fornecimento de instrumentos de gestão de documentos (regulação de documentos, etc.).

- Captura de documentos.

- Gestão profissional de arquivos eletrônicos e gestão de documentos.

- Avaliação de documentos.

- Arquivamento de acordo com a Lei do Arquivo de Hamburgo para todas as instituições da Universidade de Hamburgo.

- Conselho arquivístico na busca de documentos históricos da Universidade de Hamburgo.

- Acesso aos arquivos para fins científicos, jornalísticos e pessoais na sala de leitura.

$\mathrm{Na}$ Alemanha existe a lei federal de Arquivos, chamada Bundesarchivgesetz (BArchG), que discorre sobre a utilização e proteção dos arquivos do governo federal a cargo do Arquivo Federal (Bundesarchiv) e nos estados também existem as leis de arquivos de cada um, sob a coordenação dos arquivos estaduais que regem suas ações e de seus arquivos subordinados, geralmente tem muitas características da lei federal. No caso a universidade segue a lei de arquivos do estado de Hamburgo, a Hamburgisches Archivgesetz (HmbArchG) e a partir daí criaram a "ordem para os arquivos da universidade" (Ordnung für das Universitätsarchiv Hamburg), uma espécie de regulamento para as especificidades da universidade. 
No que concerne aos instrumentos arquivísticos foram criados três materiais de orientação: o guia de diretrizes para gestão de documentos, um plano de arquivos com o tempo de retenção dos documentos e o guia com regras para digitalização.

As diretrizes para gestão de documentos (LEITFADEN ZUR SCHRIFTGUTVERWALTUNG) é voltada para o pessoal da administração e discorre sobre a criação, recepção, uso, manutenção e guarda dos documentos nas áreas de trabalho. Ela é baseada na norma ISO $15489-1^{3}$ e substitui um livro de regras da administração de 1975. O instrumento discorre "os objetivos da gestão de documentos podem ser resumidos com as três palavras-chave sustentabilidade, segurança jurídica e economia." (LEITFADEN ZUR SCHRIFTGUTVERWALTUNG, 2018, tradução nossa).

O outro instrumento é o chamado Aufbewahrungsfristen Fristenkatalog für die Universität Hamburg que é um plano de arquivos que contém os assuntos gerais e as espécies documentais com seus períodos de armazenamento. Ele não é um instrumento exaustivo, tem um caráter bem geral e estar sujeito a alterações, adições e atualizações, desde que as áreas entrem em contato com o arquivo. Os períodos de retenção começam com o encerramento dos documentos e após a expiração do prazo nenhum documento deve ser destruído sem o conhecimento da equipe do arquivo. Em geral o período de retenção após o encerramento é de dez anos, mas existem as exceções.

Uma vez terminado o período de armazenamento, a equipe do arquivo deve ser informada para a avaliação dos documentos. O que se refere a ensino e pesquisa geralmente é mantido. Mas outros aspectos são levados em discussão na avaliação, que é feita por no mínimo dois arquivistas.

\footnotetext{
${ }^{3}$ Define os conceitos e princípios a partir dos quais são desenvolvidas abordagens para a criação, captura e gestão de documentos. "Esta é a primeira Norma ISO na área de documentação e informação e direciona sua atenção aos processos que garantem um sistemático controle da produção, uso, manutenção e eliminação de documentos" (INDOLFO, 2012, p. 18).
} 
Figura 2 - Aufbewahrungsfristen Fristenkatalog für die Universität Hamburg

UNIVERSITĀTSARCHIN

HANDREICHUNG NR. 1- AUFBEWAHRUNGSFRISTEN

STAND: AUGUST 2017

\begin{tabular}{|l|c|}
\hline Aufzeichnungen & $\begin{array}{c}\text { Aufbewahrungsfristen } \\
\text { [in Jahren] }\end{array}$ \\
\hline \hline Abtretungserklärungen & 10 \\
\hline Aktenordnungen, -pläne und -verzeichnisse & 30 \\
\hline Angebotsunterlagen & 10 \\
\hline $\begin{array}{l}\text { Annullierungsbelege (Storno eines internen/externen } \\
\text { Geschäftsvorfalls) }\end{array}$ & 10 \\
\hline Arbeitsablaufuntersuchungen, Arbeitsanalysen & 10 \\
\hline
\end{tabular}

Fonte: Print de tela do instrumento (Universitätsarchiv Hamburg, 2019)

Os documentos considerados eliminados são colocados em uma espécie de caixa lacrada (foto abaixo) e levadas por uma empresa responsável pelo processo de eliminação.

\section{Fotografia 1 - Caixa para documentos eliminados}

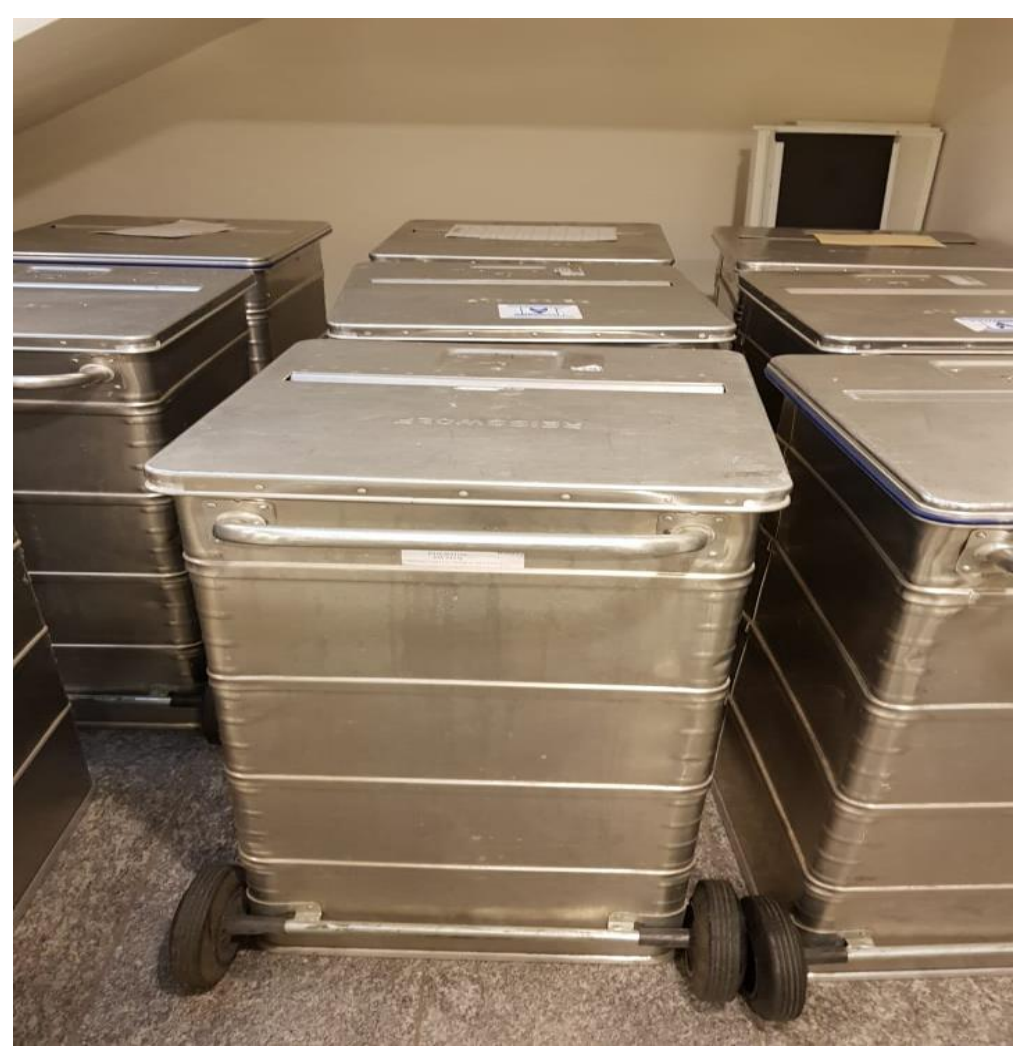

Fonte: Fotografia feito pelo autor (2019)

A questão da avaliação de documentos na Alemanha é muito complexa. Desde meados dos anos 1990 há profícuas discussões sobre o tema e alguns 
direcionamentos. Segundo Taylor (2016) essas discussões concentraram-se tanto em abordagens locais como estrangeiras "(including Menne-Haritz's mediation of Schellenbergian concepts, the American documentation strategy advocated by Helen Samuels, the Dutch PIVOT strategy, the idea of the intermediate archive pioneered by NARA and Canadian Terry Cook's macroappraisal approach)" (TAYLOR, 2016, p. 15). Para a autora as principais iniciativas locais foram:

As principais iniciativas foram 0 modelo Federführungs desenvolvido pela Bundesarchiv (Arquivos Federais), a abordagem de avaliação horizontal e vertical do Landesarchiv (Arquivos do Estado) de Baden-Württemberg - não muito diferente da macro-avaliação - e os planos de documentação típicos de nível municipal e dos arquivos universitários. Houve também um novo foco na gestão de documentos e nas possibilidades de colaboração na avaliação entre diferentes instituições (reconhecidamente, este esboço amplo é um pouco simplista, por exemplo, a abordagem do plano de documentação delineada por Becker em 2009 também apresenta a utilização da avaliação horizontal e vertical e a cooperação com outros arquivos). (TAYLOR, 2016, p. 14-15, tradução nossa)

Existem importantes autores (Robert Kretzschmar, Angelika MenneHaritz, Irmgard Christa Becker, entre outros) e trabalhos sobre o assunto, a maioria em alemão, que não é objetivo do trabalho discorrer, mas no caso específico das universidades um trabalho chamado Perfil da Documentação para os Arquivos das Universidades Acadêmicas (DAS DOKUMENTATIONSPROFIL FÜR ARCHIVE WISSENSCHAFTLICHER HOCHSCHULEN) tem sido cada vez mais utilizado como referência na área universitária alemã.

Por meio de uma conferência organizada pelo Arquivo da Universidade de Saarbrücken em 2006 um grupo de discussão da Associação dos Arquivistas Alemães nominada arquivos de universidades e instituições científicas dedicouse ao tema avaliação. Das palestras e discussões resultou um segundo grupo de trabalho que nos anos seguintes, mais precisamente em 2009, culminou na publicação de um perfil de documentação para os arquivos universitários, resumindo o status da discussão de avaliação no ensino superior e servindo ao mesmo tempo como um guia para o trabalho prático.

Plassmann (2009), um dos autores do referido trabalho, em artigo publicado em uma das principais revistas alemãs discorre: 
Os fundos e coleções de arquivos universitários contêm uma ampla variedade de registros e itens, que devem refletir os fundamentos da história da universidade como um todo e em detalhes essenciais. A fim de atender a falta mais ou menos grave de recursos que quase todos arquivos universitários têm, fundos devem ser mantidos tão pequenos quanto possível sem cair abaixo de um certo nível. Os requisitos para documentação agora publicados são formulados por um grupo de trabalho de arquivistas das universidades. Eles sugerem uma maneira de garantir os arquivos mais importantes, e evitando acumular os não tão importantes, focando em fontes concentradas e condensadas e valor de suas informações, e integrando todos os fundos e coleções em um único sistema. (PLASSMANN, 2009, p. 137, tradução nossa)

As grandes áreas foram divididas em:

1. A Instituição Universidade (com todos os aspectos organizacionais, legais, condições de pessoal e infraestrutura, bem como planejamento e contatos externos).

2. Pesquisa e ensino como tarefas principais (com exames e atribuição de título);

3. Organizações estudantis.

4. Deduções (principalmente de professores).

5. Outras coleções (com fotos, objetos tridimensionais, documentos sonoros, filmes, auto apresentação e cobertura da mídia bem como acadêmico, cultural e esportivo).

A estrutura se dá por grandes assuntos e vai desdobrando em subgrupos como uma espécie de plano de classificação e segundo Plassmann o perfil da documentação é, no entanto, entendido também aqui como um guia, não como receita e é aberto para soluções individuais/próprias.

Voltando a universidade de Hamburgo ainda existe o guia regras de digitalização e gravação (Scan- und Erfassungsregeln), cuja a política se aplica ao manuseio de arquivos eletrônicos na universidade. Em relação aos documentos digitais eles estão estudando como atuar e nas universidades de um modo geral ainda é um campo complexo, onde cada estado estuda a sua melhor solução para um grande problema presente-futuro já identificado. 


\section{Fotografia 2 - Caixa-arquivo com a etiqueta de identificação}

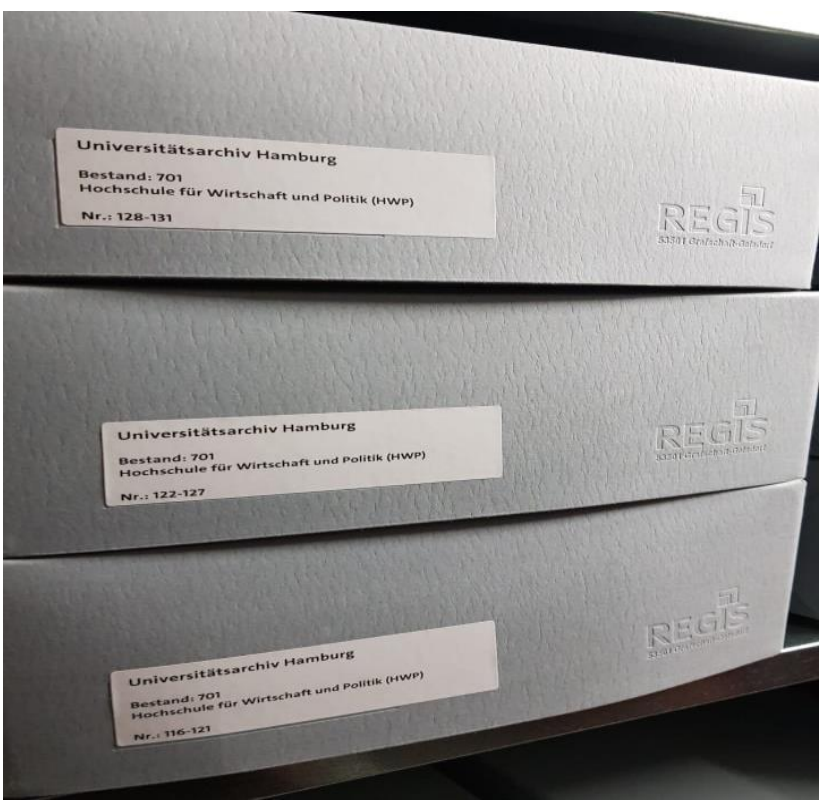

Fonte: Fotografia feita pelo autor (2019)

\section{Fotografia 3 - Cartão de Matrícula}

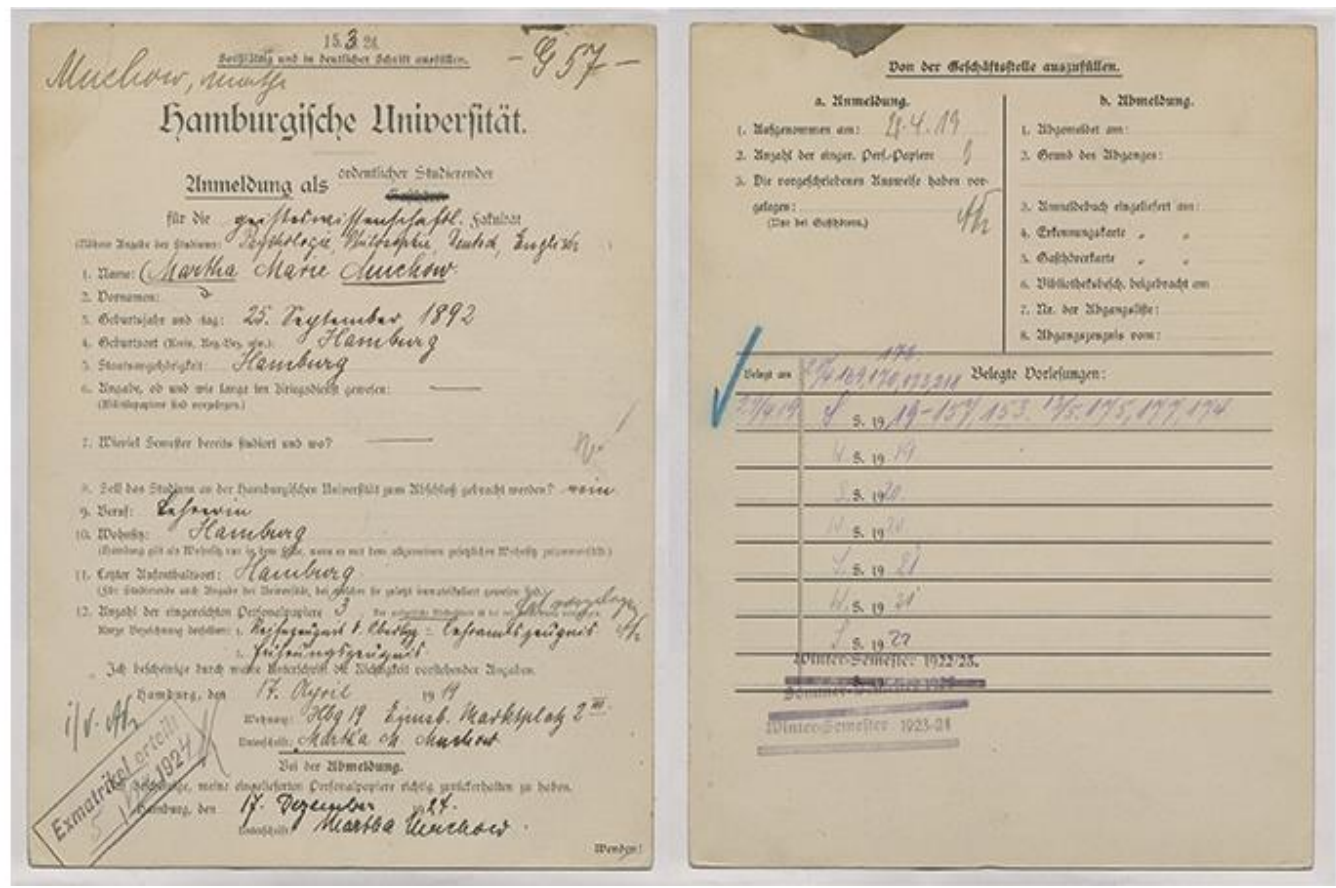

Fonte: Universitätsarchiv Hamburg - Cartão de Matrícula de 1919

\section{CONSIDERAÇÕES FINAIS}

A Universidade de Hamburgo tem uma média de idade parecida com das universidades brasileiras, e é perceptível a preocupação com os seus 
documentos e a preservação de sua história, refletida na sua estrutura física e de recursos humanos, ao passo que no Brasil, na maioria das universidades ainda não existe essa realidade desejável.

É importante ressaltar que antes desta experiência de intercâmbio não havia ideia de como eram os arquivos alemães, até mesmo pela escassa bibliografia sobre o tema. $O$ contato in loco com arquivos e profissionais da área de outros países proporciona uma grande oportunidade de aprendizado.

Mais importante ainda é saber que no Brasil, em termos de teoria e gestão de boas práticas, não está atrás em nada de um país como a Alemanha.

O que esse momento mostrou é que algumas instituições, universidades precisam de mais atenção, mais recursos humanos especializados, infraestrutura adequada de arquivo, pois ainda que os arquivos alemães enfrente problemas, e eles tem, ainda sim eles estão a frente, pois garatem o mínimo para o trabalho a ser feito.

\section{AGRADECIMENTOS}

À Diretoria de Arquivos Institucionais - DIARQ da Universidade Federal de Minas Gerais pela autorização do afastamento para realizar o intercâmbio na Alemanha.

À equipe de arquivistas, em especial Jens Geinitz, do Arquivo da Universidade de Hamburgo pela atenção, recepção e suporte em todo o processo da visita técnica.

\section{REFERÊNCIAS}

ARQUIVO NACIONAL. Dicionário brasileiro de terminologia arquivística. Rio de Janeiro: Arquivo Nacional, 2005. Disponível em: http://www.arquivonacional.gov.br/images/pdf/Dicion_Term_Arquiv.pdf. Acesso em: 12 mar. 2019.

BELLOTO, Heloísa Liberalli. Universidades e arquivos: perfil, história e convergência. Transinformação, v. 1, n. 3, p. 15-28, set/dez, 1989. Disponível em:

http://periodicos.puccampinas.edu.br/seer/index.php/transinfo/article/view/1679. Acesso em 08 fev. 2019. 
CARPES, Franciele Simon; FLORES, Daniel. O Arquivo Universitário e a Memória da Universidade. Inf. \& Soc.: Est., João Pessoa, v. 23, n. 3, p. 13-22, set./dez. 2013. Disponível em:

http://www.periodicos.ufpb.br/ojs/index.php/ies/article/view/12278 Acesso em: 12 mar. 2019.

CHAUI, Marilena. A universidade pública sob nova perspectiva. Revista Brasileira de Educação, n. 24, set/dez, 2003. Disponível em: http://www.scielo.br/pdf/rbedu/n24/n24a02.pdf. Acesso em 08 fev. 2019.

INDOLFO, Ana Celeste. Avaliação de documentos de arquivo: atividade estratégica para a gestão de documentos. Revista do Arquivo Geral da Cidade do Rio de Janeiro, n. 6, 2012, p. 13-37. ISSN 1983-6031.

JARDIM, José Maria. A invenção da memória nos arquivos públicos. Ciência da Informação, Brasília, v. 25, n. 2, 1995. Disponível em:

http://revista.ibict.br/ciinf/article/view/659. Acesso em 12 mar. 2019.

MENEZES, João Luiz. A segurança dos arquivos universitários e a missão institucional. ÁGORA, Florianópolis, v. 22, n. 44, p. 61-87, 2012. Disponível em: http://oaji.net/articles/2015/2526-1450012600.pdf. Acesso em: 23 jan. 2019. ISSN 0103-3557

MERLO, Franciele; KONRAD, Glaucia Vieira Ramos. Documento, História e Memória: a importância da preservação do patrimônio documental para o acesso à informação. Inf. Inf., Londrina, v. 20, n. 1, p. 26 - 42, jan./abr. 2015. Disponível em:

http://www.uel.br/revistas/uel/index.php/informacao/article/view/18705/pdf_43. Acesso em: 02 dez. 2018.

PEREIRA, Elisabete Monteiro de Aguiar. A universidade da modernidade nos tempos atuais. Avaliação, Campinas; Sorocaba, SP, v. 14, n. 1, p. 29-52, mar. 2009. Disponível em: http://www.scielo.br/scielo.php?pid=S1414-

40772009000100003\&script=sci_abstract\&tlng=pt. Acesso em 08 fev. 2019.

PEREIRA, Fernanda Cheiran. Arquivos, memória e justiça: Gestão documental e preservação de acervos judiciais no Rio Grande do Sul. 2011. 173 f. Trabalho de Conclusão de Curso (Bacharel em Arquivologia) Universidade Federal do Rio Grande do Sul, Porto Alegre, 2011. Disponível em: http://www.lume.ufrgs.br/handle/10183/31152. Acesso em: 12 mar. 2019.

PLASSMANN, Max. Das Dokumentationsprofil fur Archive wissenschaftlicher Hochschulen. Archivar Zeitschrift für Archivwesen, v. 62, n. 2, p. 132-137, May 2009. Disponível em:

http://www.archive.nrw.de/archivar/hefte/2009/ausgabe2/ARCHIVAR_0209_internet.pdf. Acesso em 09 jan. 2019. 
SIMÕES, Mara Leite. O surgimento das universidades no mundo e sua importância para o contexto da formação docente. Revista Temas em Educação, João Pessoa, v. 22, n. 2, p. 136-152, jul.-dez. 2013. Disponível em: http://www.periodicos.ufpb.br/ojs/index.php/rteo/article/view/17783. Acesso em 08 fev. 2019.

TAYLOR, Isabel. The German appraisal discussion since 1990: na Overview. Archives and Manuscripts, v. 44, n. 1, p. 14-23, 2016. Disponível em: http://dx.doi.org/10.1080/01576895.2015.1136226. Acesso em 31 jan. 2019.

Universitätsarchiv Hamburg (Deutschland). Organigramm (2019). Disponível em: https://www.archiv.uni-hamburg.de/dokumente/organigramm-uahh20190228.pdf. Acesso em: 20 jan. 2019.

Universitätsarchiv Hamburg (Deutschland). Über uns (2019). Disponível em: https://www.archiv.uni-hamburg.de/ueber-uns.html. Acesso em: 20 jan. 2019.

Universitätsarchiv Hamburg (Deutschland). Leitfaden zur

Schriftgutverwaltung (2019). Disponível em: https://www.archiv.unihamburg.de/dokumente/leitfaden-zur-schriftgutverwaltung-20181006.pdf.

Acesso em: 20 jan. 2019.

Universitätsarchiv Hamburg (Deutschland). Aufbewahrungsfristen.

Fristenkatalog für die Universität Hamburg (2019). Disponível em: https://www.archiv.uni-hamburg.de/dokumente/fristenkatalog-20170816pdf.pdf. Acesso em: 20 jan. 2019.

Universitätsarchiv Hamburg (Deutschland). Scan- und Erfassungsregeln für die elektronische aktenführung an der Universität Hamburg (2019). Disponível em: https://www.archiv.uni-hamburg.de/dokumente/scan-underfassungsregeln-20180131.pdf. Acesso em: 20 jan. 2019.

\title{
UNIVERSITY ARCHIVES: THE CASE OF THE UNIVERSITY OF HAMBURG
}

\begin{abstract}
Introduction: The paper discusses the universities and their archives and reports an experience in the archive of the University of Hamburg. Objective: it was intended to expand knowledge about a little-known archival reality. Methodology: A bibliographical research and technical visit to the archive of the university to know the work was done. Results: The University of Hamburg has a good management and physical structure and has archival instruments for the organization of archives. Conclusions: The concern of the University of Hamburg with the preservation of its history through its documents was noticeable. Brazil, in terms of theory and management of good practices, is not far behind a country like Germany,
\end{abstract}


what some institutions need is more specialized human resources and adequate archive infrastructure.

Descriptors: University. Archives. University of Hamburg. University Archives.

\title{
ARCHIVOS UNIVERSITARIOS: EL CASO DE LA UNIVERSIDAD DE HAMBURGO
}

\begin{abstract}
RESUMEN
Introducción: El trabajo discurre sobre las universidades y sus archivos y relata una experiencia en el archivo de la Universidad de Hamburgo. Objetivo: Se pretendió expandir el conocimiento sobre una realidad archivística poco conocida. Metodología: Se realizó investigación bibliográfica y visita técnica al archivo de la universidad para conocer el trabajo. Resultados: La Universidad de Hamburgo tiene una buena estructura de gestión y física y cuenta con instrumentos archivísticos para la organización de los archivos. Conclusiones: Esa experiencia proporcionó ampliar el campo de visión sobre los archivos universitarios en Alemania y hacer un paralelo con la realidad brasileña. Fue notable la preocupación de la Universidad de Hamburgo con la preservación de su historia a través de sus documentos fue notable. Brasil, en términos de teoría y gestión de buenas prácticas, no está muy lejos de un país como Alemania, lo que algunas instituciones necesitan son recursos humanos más especializados y una infraestructura de archivos adecuada.
\end{abstract}

Descriptores: Universidad. Archivos. Universidad de Hamburgo. Archivos universitarios.

Recebido em: 30/09/2019

Aceito em: 13/04/2020 